\title{
The Dopamine Transporter: Comparative Ultrastructure of Dopaminergic Axons in Limbic and Motor Compartments of the Nucleus Accumbens
}

\author{
Melissa J . Nirenberg, ${ }^{1}$ J une Chan, ${ }^{1}$ Alicia Pohorille, ${ }^{1}$ Roxanne A. Vaughan, ${ }^{2}$ George R. Uhl, ${ }^{3,4}$ \\ Michael J . Kuhar, ${ }^{5}$ and Virginia M. Pickel ${ }^{1}$ \\ ${ }^{1}$ Department of Neurology and Neuroscience, Cornell University Medical College, New York, New York 10021, \\ ${ }^{2}$ Neuroscience and 3 Molecular Neurobiology Branches, National Institute on Drug Abuse, Baltimore, Maryland 21224, \\ ${ }^{4}$ Departments of Neurology and Neuroscience, J ohns Hopkins University School of M edicine, Baltimore, Maryland \\ 21224, and 5Neuroscience Division, Yerkes Regional Primate Center, Emory University, Atlanta, Georgia 30322
}

The dopamine transporter (DAT) regulates extracellular dopamine concentrations, transports neurotoxins, and acts as a substrate for cocaine reinforcement. These functions are known to differ in the limbic-associated shell and motor-associated core compartments of the nucleus accumbens (NAC). Previous studies have shown differential expression of DAT in the NAc shell and core but were limited in resolution to the regional level. Thus, it is not known whether there are differences in the amount, subcellular localization, or plasmalemmal targeting of DAT within individual dopaminergic axons in the two regions. We used high-resolution electron microscopic immunocytochemistry to investigate these possibilities. We show that in both the shell and core, DAT immunogold labeling is present in tyrosine hydroxylase-immunoreactive varicose axons that form symmetric synapses. Within these labeled axons, most DAT gold particles are located on extrasynaptic plasma membranes, but some are associated with intracellular membranes. Dopaminergic axons in the shell contain lower mean densities of both total DAT gold particles (per square micron) and plasmalemmal DAT gold particles (per micron) than those in the core. Within labeled axons in the NAc shell and core, however, there are no detectable differences in the subcellullar distribution of DAT or the percentage of total DAT gold particles that are located on plasma membranes. These studies are the first to examine and compare the subcellular localization of DAT in the NAc shell and core. As a result, they identify intrinsic, cell-specific differences in the expression of DAT within dopaminergic axons in these functionally distinct striatal compartments.

Key words: dopamine transporter; dopamine reuptake; immunogold; accumbens; striatum; cocaine; amphetamine
Midbrain dopaminergic neurons in the ventral tegmental area (VTA) and substantia nigra (SN) modulate a wide variety of functions, including motivation, attention, reward, and locomotor activity (Le Moal, 1995). In addition, these neurons are the major targets of drugs of abuse such as cocaine and amphetamines (for review, see Koob and Bloom, 1988; Kuhar et al., 1991; Fibiger et al., 1992). The rewarding and reinforcing properties of these drugs are believed to involve mesolimbic dopaminergic projections to the shell of the nucleus accumbens (NAc), a region that is closely linked with limbic structures and functions (Voorn et al., 1989; Heimer et al., 1991; Deutch and Cameron, 1992; O’Donnell and Grace, 1993; Zahm and Heimer, 1993; Jongen-Relo et al., 1994). In contrast, the motor effects of these drugs are more strongly associated with nigrostriatal dopaminergic projections to dorsal regions of the striatum, including the caudate-putamen nucleus and the NAc core (for review, see Brog, 1992; Roth and Elsworth, 1995).

Received May 5, 1997; revised July 1, 1997; accepted July 1, 1997.

M.J.N. is supported by National Institute of Mental Health (NIMH) Grant MH40342. V.M.P. receives salary support from NIMH Grant MH00078 and research support from National Institute on Drug Abuse (NIDA) Grant DA04600 and NIMH Grant MH40342. R.A.V. and G.R.U. are supported by the Intramural Research Program, NIDA. M.J.K. is supported by National Institutes of Health Grant RR00165. We thank Drs. Carrie T. Drake, Adena L. Svingos, and Richard H. Savel for helpful critical commentary.

Correspondence should be addressed to Dr. Melissa J. Nirenberg, Department of Neurology and Neuroscience, Cornell University Medical College, 411 East 69th Street, Room KB-410, New York, NY 10021.

Copyright (c) 1997 Society for Neuroscience 0270-6474/97/176899-09\$05.00/0
Recent evidence has suggested that many of the functional differences between the NAc shell and core may be attributable to differential expression of the plasmalemmal dopamine transporter (DAT) in these regions (for review, see Bannon et al., 1995). DAT plays a critical role in regulating the extracellular levels of dopamine (Horn, 1990; Giros et al., 1996) and is the principal "receptor" involved in the reinforcing properties of cocaine and other stimulants (Ritz et al., 1987; Kuhar et al., 1991). Extracellular dopamine concentrations in the shell and core also show differential sensitivity to psychostimulants (Pontieri et al., 1995; Jones et al., 1996), consistent with known compartmental differences in DAT binding sites (Sharpe et al., 1991; Jones et al., 1996). Some of the responses to psychostimulant administration (Pontieri et al., 1994; Pierce and Kalivas, 1995) and withdrawal (Pilotte et al., 1996) occur selectively in the NAc shell but not the core. Moreover, the shell is less susceptible to neurotoxins such as 6-hydroxydopamine (6-OHDA) that are taken up by DAT (Zahm, 1991), providing additional indirect evidence that there may be functional differences in expression of DAT within limbic and motor compartments of the NAc.

Previous studies showing differences in dopamine uptake in the NAc core and shell (Sharpe et al., 1991; Jones et al., 1996) were limited in resolution to the regional level. Thus, fundamental questions remain unanswered regarding whether the unique functional characteristics of the NAc shell and core reflect cell-specific differences in the amount, subcellular localization, or plasmalemmal targeting of this transporter in the two regions. The 
recent cloning (Giros et al., 1991; Kilty et al., 1991; Shimada et al., 1991) and production of high-titer antisera against rat DAT (Freed et al., 1995; Revay et al., 1996) now make it possible to address these questions directly. In the present study, we therefore used electron microscopic immunocytochemistry to examine and compare the precise subcellular localization of DAT in the NAc shell and core of rat brain.

\section{MATERIALS AND METHODS}

Tissue preparation. Methods for tissue preparation and immunocytochemical labeling were based on those of Leranth and Pickel (1989) as described previously (Nirenberg et al., 1996a). Five adult, male Sprague Dawley rats $(250-400 \mathrm{gm})$ were anesthetized with sodium pentobarbital $(50 \mathrm{mg} / \mathrm{kg}$, i.p.) and perfused through the ascending aorta with $40 \mathrm{ml}$ of heparin $(1000 \mathrm{U} / \mathrm{ml}$ heparin in $0.15 \mathrm{M} \mathrm{NaCl}), 50 \mathrm{ml}$ of $3.75 \%$ acrolein, and $2 \%$ paraformaldehyde in $0.1 \mathrm{M}$ phosphate buffer $(\mathrm{PB}), \mathrm{pH}$ 7.4. The brains were removed from the calvariae and post-fixed for $30 \mathrm{~min}$ in $2 \%$ paraformaldehyde. Sections through the NAc $(30-40 \mu \mathrm{m})$ were cut with a vibratome, and incubated in $1 \%$ sodium borohydride in PB for $30 \mathrm{~min}$. To enhance the penetration of the immunoreagents, the sections were cryoprotected for $15 \mathrm{~min}$ in $25 \%$ sucrose and $3.5 \%$ glycerol in $0.05 \mathrm{M} \mathrm{PB}$, rapidly frozen in chlorodifluoromethane followed by liquid nitrogen, and immediately thawed in room temperature PB.

Antisera. As in previous studies (Nirenberg et al., 1996a, 1997; Pickel et al., 1996; Nirenberg and Pickel, 1997), we used two well characterized antisera: a rabbit polyclonal anti-peptide antiserum directed against the N-terminal domain of rat DAT (Freed et al., 1995; Revay et al., 1996) and a commercially available mouse monoclonal antiserum directed against TH (Incstar, Stillwater, MN). Free-floating tissue sections were incubated overnight at room temperature in $0.1 \%$ bovine serum albumin (BSA)-Tris-saline (TS; $0.9 \% \mathrm{NaCl}$ in $0.1 \mathrm{M}$ Tris, $\mathrm{pH}$ 7.6) to which one of the following had been added: (1) a 1:6000 or 1:3000 dilution of the DAT antiserum, for single labeling; (2) a 1:6000 dilution of the DAT antiserum and a 1:10,000 dilution of the TH antiserum, for double labeling; or (3) no primary antiserum, as a negative control.

Immunocytochemical labeling. In tissue that was prepared for dual labeling, the bound TH antiserum was identified using the avidin-biotin complex method (Hsu et al., 1981) as follows. The sections were incubated for $30 \mathrm{~min}$ in a 1:400 dilution of biotinylated goat anti-mouse IgGs in $0.1 \% \mathrm{BSA}$, for $30 \mathrm{~min}$ in a 1:100 dilution of avidin-biotin-peroxidase complex, and then for $6 \mathrm{~min}$ in a solution consisting of $22 \mathrm{mg}$ of $3,3^{\prime}$-diaminobenzidine and $10 \mu \mathrm{l}$ of $30 \%$ hydrogen peroxide in $100 \mathrm{ml}$ of 0.1 м TS, pH 7.6.

All tissue sections were prepared for immunogold labeling (Chan et al., 1990) as follows. They were incubated for $2 \mathrm{hr}$ in a 1:50 dilution of colloidal gold $(1 \mathrm{~nm})$-conjugated anti-rabbit IgG (Amersham, Arlington Heights, IL), and fixed for $10 \mathrm{~min}$ in $2 \%$ glutaraldehyde in PBS. The immunogold particles were then intensified for $6 \mathrm{~min}$ with a silver solution using a light-stable intenSEM kit (Amersham).

Electron microscopy. All tissue sections were incubated in $2 \%$ osmium tetroxide for $60 \mathrm{~min}$, dehydrated in a series of graded ethanols and propylene oxide, and then embedded in Epon 812 between two pieces of Aclar plastic. Ultrathin sections from the NAc core and medial NAc shell (Fig. 1), derived from rostrocaudal sections between +1.20 and +1.70 from bregma (Paxinos and Watson, 1986), were collected from the outer surface of the plastic-embedded tissue with an ultramicrotome (Research and Manufacturing Co., Tucson, AZ). These sections were then counterstained with lead citrate and uranyl acetate and examined with a Philips (Mahwah, NJ) electron microscope.

The electron micrographs that were used for illustrations were prepared on a Power Macintosh 8500/150 Computer (Apple Computer Inc., Cupertino, CA) as follows. They were scanned with an AGFA Arcus II scanner (Agfa-Gevaert, NV, Montsel, Belgium) in combination with FotoLook (Agfa-Gevaert) and Photoshop (version 3.0.4; Adobe Systems Inc., Mountain View, CA) software. Composite figures were then prepared and labeled using QuarkXPress (version 3.32; Quark Inc., Denver, $\mathrm{CO}$ ) and Adobe Illustrator (version 6.0) software.

Identification of labeled profiles. The classification of labeled profiles and subcellular organelles was based on the criteria of Peters et al. (1991). Synaptic junctions were defined by the presence of a junctional complex, a restricted zone of parallel membrane appositions with slight enlargement of the extracellular space, and associated membrane densities. Symmetric synapses were characterized by presynaptic and postsyn-

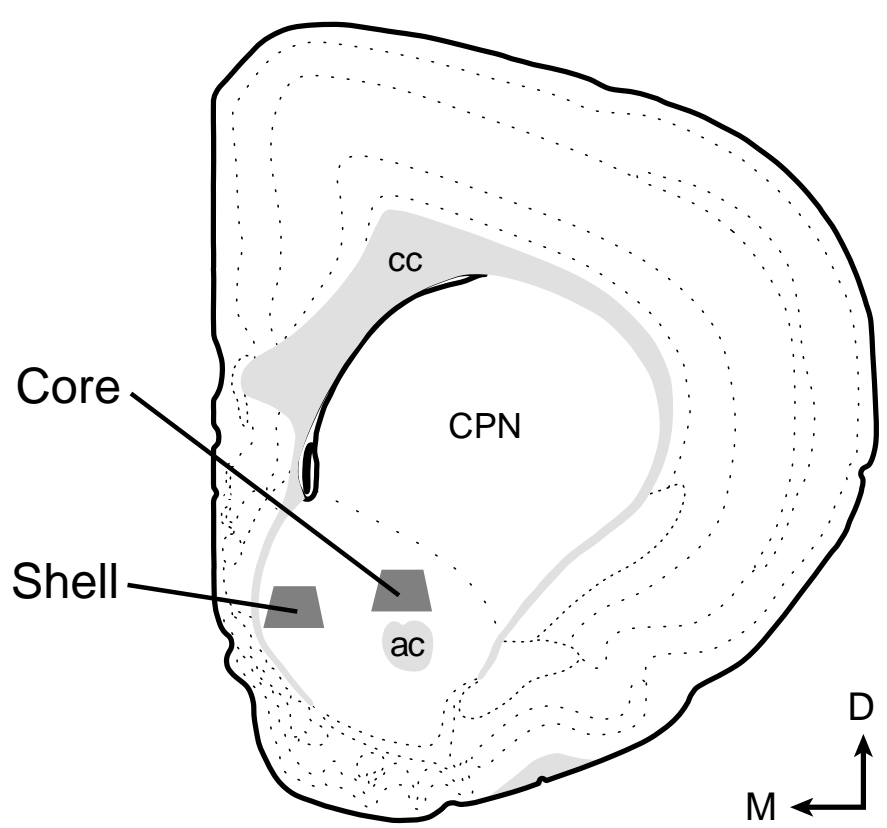

Figure 1. Coronal hemisection of the rat forebrain. Schematic diagram illustrating the regions of the NAc shell (left) and core (right) that were sampled for electron microscopic analysis. The illustration is shown at a level $+1.70 \mathrm{~mm}$ from bregma. $a c$, Anterior commissure; $c c$, corpus callosum; $C P N$, caudate-putamen nucleus. The arrows point dorsal $(D)$ and medial (M). Modified from Swanson (1992).

aptic densities of similar thickness. In contrast, asymmetric synapses were characterized by postsynaptic densities that were thicker than the presynaptic density. Appositions (nonsynaptic contacts) were identified as sites of closely spaced parallel plasma membranes that were not separated by glial processes but that lacked detectable synaptic junctions. In the present study, the term "axon" was used to refer collectively to both narrow intervaricose axonal segments $(<0.1 \mu \mathrm{m}$ in maximal crosssectional diameter) and to larger-diameter axonal varicosities. The term "axon terminal" was used to refer to vesicle-filled neuronal profiles that formed obvious synaptic specializations, regardless of their diameter.

Identification of subcellular organelles. Small synaptic vesicles (SSVs) were identified by their $30-60 \mathrm{~nm}$ cross-sectional diameter, round to pleomorphic shape, and electron-lucent lumen. Large dense core vesicles (DCVs) were identified by their size $(80-120 \mathrm{~nm}$ in cross-sectional diameter) and the presence of an electron-dense core surrounded by an electron-lucent halo. Tubulovesicles were defined as electron-lucent membranous structures that were irregular in shape and larger than SSVs ( $>70 \mathrm{~nm}$ in maximal cross-sectional area).

Data analysis. Quantitative analysis was performed on a Dell (Austin, TX) 466/T computer, using a Microcomputer Imaging Device system (Imaging Research Inc., St. Catherines, Ontario, Canada). DAT-labeled axons were sampled from four experimental animals. A total of eight paired tissue sections of the NAc core and shell, derived from the either the same (six of eight cases) or adjacent (two of eight cases) vibratome sections were examined. For each pair of sections, data were collected from a minimum of 50 nonoverlapping fields $\left(490 \mu \mathrm{m}^{2}\right.$ each) at the tissue-plastic interface. Quantitative analysis was performed on the first 434 DAT-immunoreactive axons that were detected within each of the two NAc compartments. For each of these processes, the following was determined: (1) the total number of immunogold particles (plasmalemmal and intracellular) located within each of the labeled axons per unit area of labeled axon (in square microns); (2) the number of plasmalemmal gold particles located on each of the labeled axons per unit perimeter of plasma membrane (in microns); and (3) the percentage of the total (plasmalemmal and intracellular) immunogold particles that were located on the plasma membrane of each of the labeled axons. The results are reported as the mean \pm SEM, as calculated using Fisher's exact test. Statistical significance was defined by $p<0.05$. 


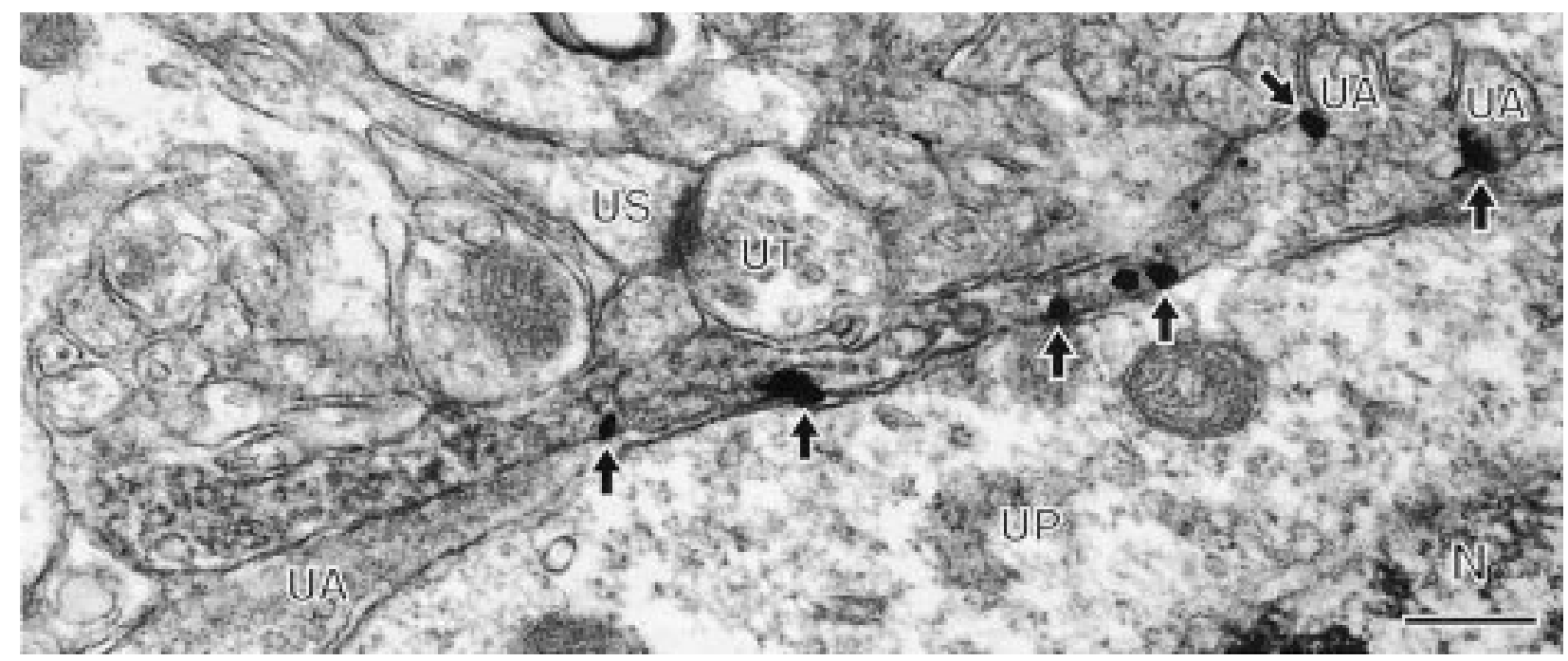

Figure 2. DAT labeling on the plasma membrane of a TH-immunoreactive axon in the NAc core. Electron micrograph showing colocalization of immunogold labeling for DAT (arrows) and immunoperoxidase labeling for TH in a varicose axon in the NAc core. The DAT immunogold labeling (arrows) is present on the plasma membranes of both the wider varicosity and the more narrow intervaricose portion of the axon. The DAT gold particles (arrows) are located near an unlabeled perikaryon $(U P)$ and several small unlabeled axons $(U A)$. The DAT-labeled axon is apposed to an unlabeled axon terminal $(U T)$ that forms an asymmetric (excitatory-type) input onto an unlabeled dendritic spine (US). $N$, Nucleus of unlabeled perikaryon. Scale bar, $0.25 \mu \mathrm{m}$.
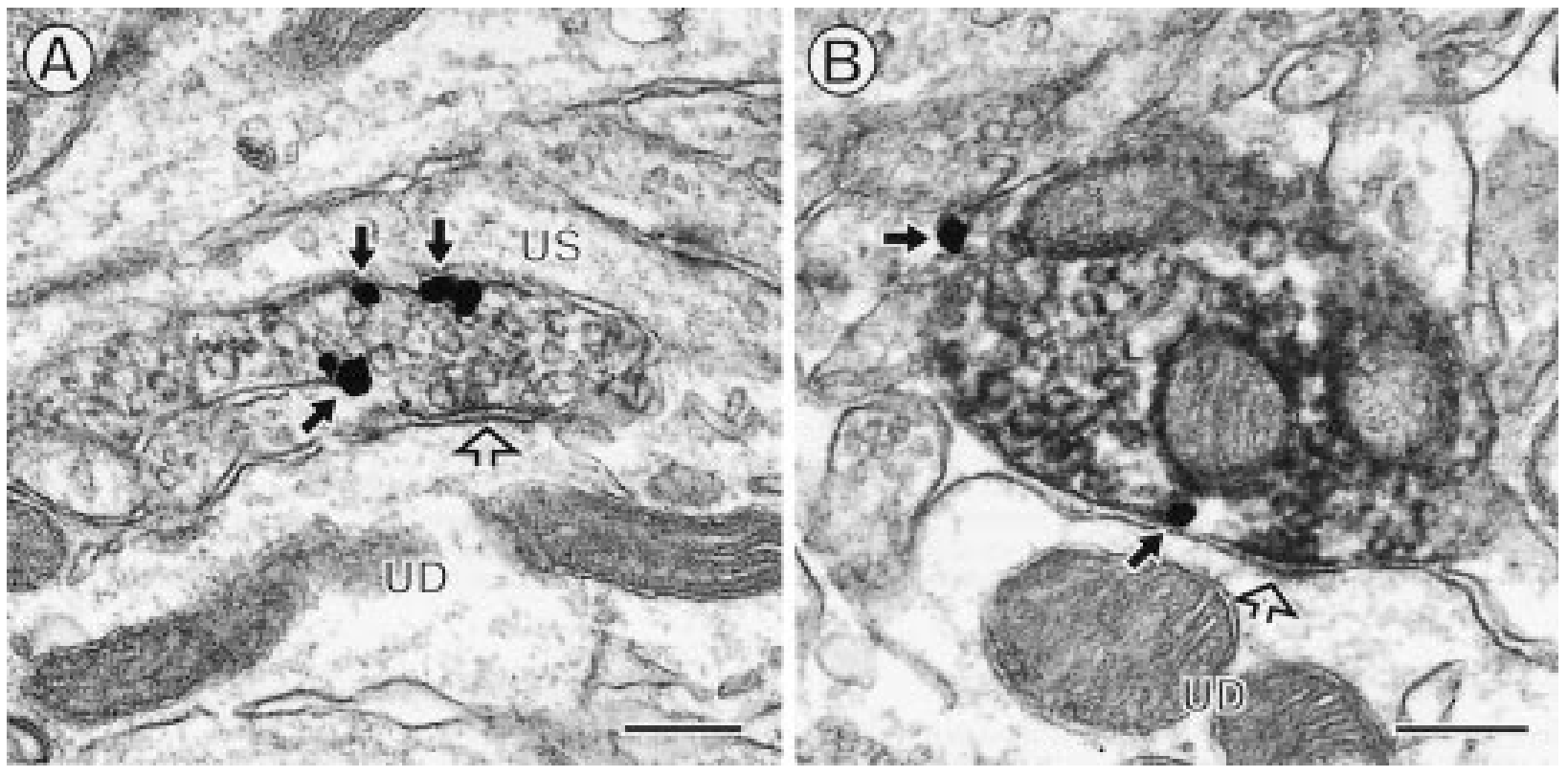

Figure 3. DAT labeling on plasma membranes of TH-immunoreactive terminals that form symmetric synapses onto dendrites. In the NAc core $(A)$ and shell $(B)$, immunogold labeling for DAT (closed arrows) and immunoperoxidase labeling for TH are colocalized within axon terminals that form symmetric synapses (open arrows) onto unlabeled dendrites (UD). The DAT gold labeling (closed arrows) is seen on extrasynaptic portions of the plasma membranes of the labeled terminals. In $A$, none of the gold particles are detected on or near the synaptic density, but some are seen near the spine (US) of the unlabeled dendrite $(U D)$. In $B$, a plasmalemmal DAT gold particle (arrow) is located near the postsynaptic dendrite. Scale bars, $0.25 \mu \mathrm{m}$.

\section{RESULTS}

\section{Specificity of the DAT immunolabeling}

Immunogold labeling for DAT was detected within unmyelinated axons and axon terminals in both the core (Figs. 2, 3A, $4 A, 5 A, 6 A$ ) and the shell (Figs. $3 B, 4 B, 5 B, 6 B, 7$ ) of the NAc. This labeling was present in ultrathin sections that were sampled from the surface of the tissue (Figs. 2-7) but was absent from control sections in which the primary antiserum had been omitted (results not shown). Within dually labeled tissue from both the core and shell of the NAc, most of the DAT-labeled axons contained peroxidase reaction product for $\mathrm{TH}$ in a single plane of section (Figs. 2-4, 6, 7A). Further analysis of serial sections through several processes revealed that DATimmunoreactive axons consistently contained $\mathrm{TH}$, whereas TH-immunoreactive axons did not always contain detectable immunogold labeling for DAT. 

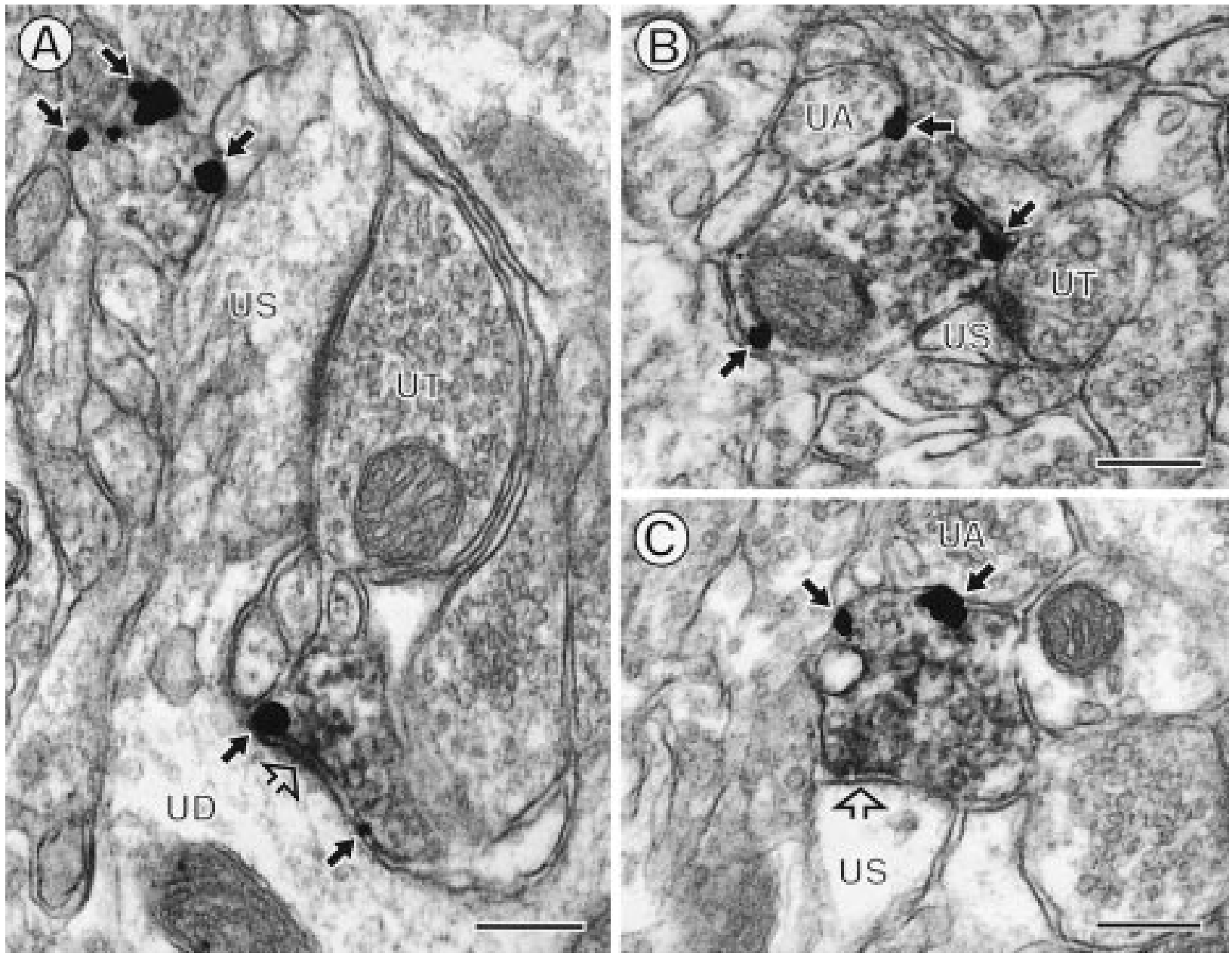

Figure 4. DAT labeling on plasma membranes of TH-immunoreactive terminals that contact unlabeled dendritic spines. Electron micrographs show colocalization of immunogold labeling for DAT (closed arrows) and immunoperoxidase labeling for TH within axons in the NAc core $(A)$ and shell $(B$, $C$ ). In $A$, a dually labeled axon terminal forms a symmetric synapse (open arrow) onto the shaft of an unlabeled dendrite (UD). The spine (US) of the unlabeled dendrite is also apposed to an axon that is dually labeled for DAT (closed arrows) and TH. In B, DAT gold particles (arrows) are seen on the plasma membrane of a TH-immunoreactive terminal near appositions with an unlabeled axon $(U A)$ and an unlabeled terminal (UT). In $C$, DAT gold particles (closed arrows) are seen on extrasynaptic portions of the plasma membrane of a TH-immunoreactive terminal. Plasmalemmal DAT gold particles are seen near appositions with an unlabeled axon (UA) but are not seen near the symmetric synapse. The DAT-labeled terminals in $A$ and $B$ are apposed to unlabeled dendritic spines $(U S)$ that receive asymmetric synapses from unlabeled axon terminals $(U T)$. Scale bars, $0.25 \mu \mathrm{m}$.

\section{Presence in axons and axon terminals}

In the core and shell, DAT labeling was seen in varicose (Figs. 2-7) and intervaricose (Fig. 2) segments of axons. These DATimmunoreactive processes only rarely formed synaptic junctions that were evident in single tissue sections. The synapses that were identified were small and symmetric, as shown in both the core (Figs. $3 A, 4 A, 5 A$ ) and the shell (Figs. $3 B, 4 C, 5 B, 7 A$ ). In some cases, these synaptic densities were discontinuous, as shown in the core (Fig. 7A), but also observed in the shell.

In both regions, DAT-immunoreactive axon terminals formed synapses predominantly onto unlabeled dendrites (Figs. 3, 4A, $5 A, 7 A$ ) and dendritic spines (Figs. $4 C, 5 B$ ) and more rarely onto unlabeled perikarya (results not shown). Many of the dendritic spines that received a symmetric synapse from a DATimmunoreactive axon terminal also received a convergent asymmetric synapse from an unlabeled axon terminal (results not shown). These synaptic relationships are typical of dopaminergic axons in this region (for review, see Pickel and Sesack, 1995).

\section{Prominent association with extrasynaptic plasma membranes}

Within the DAT-immunoreactive axons in the NAc core and shell, most of the DAT gold particles were located on cytoplasmic surfaces of the plasma membrane (Figs. 2-7). These plasmalemmal DAT gold particles appeared to be uniformly distributed on extrasynaptic portions of the plasma membranes, and thus were observed near appositions with somata (Fig. 2), dendrites (Figs. $3 B, 4 A, 5,6 B$ ), dendritic spines (Figs. $3 A, 4 A, 5 B$ ), axons (Figs. 2, $4 B, C, 6 A$ ), and astrocytes (results not shown). Although plasmalemmal DAT gold particles were observed on portions of the plasma membrane adjacent to synaptic junctions (Figs. $4 A, 5$ ), they were not detected over synaptic densities. These observations were confirmed in tissue in which the primary antiserum was used at higher concentrations to maximize the detection of DAT immunoreactivity (Fig. 5B).

A smaller number of DAT gold particles were also detected on intracellular membranes. These membranes were electron-lucent 

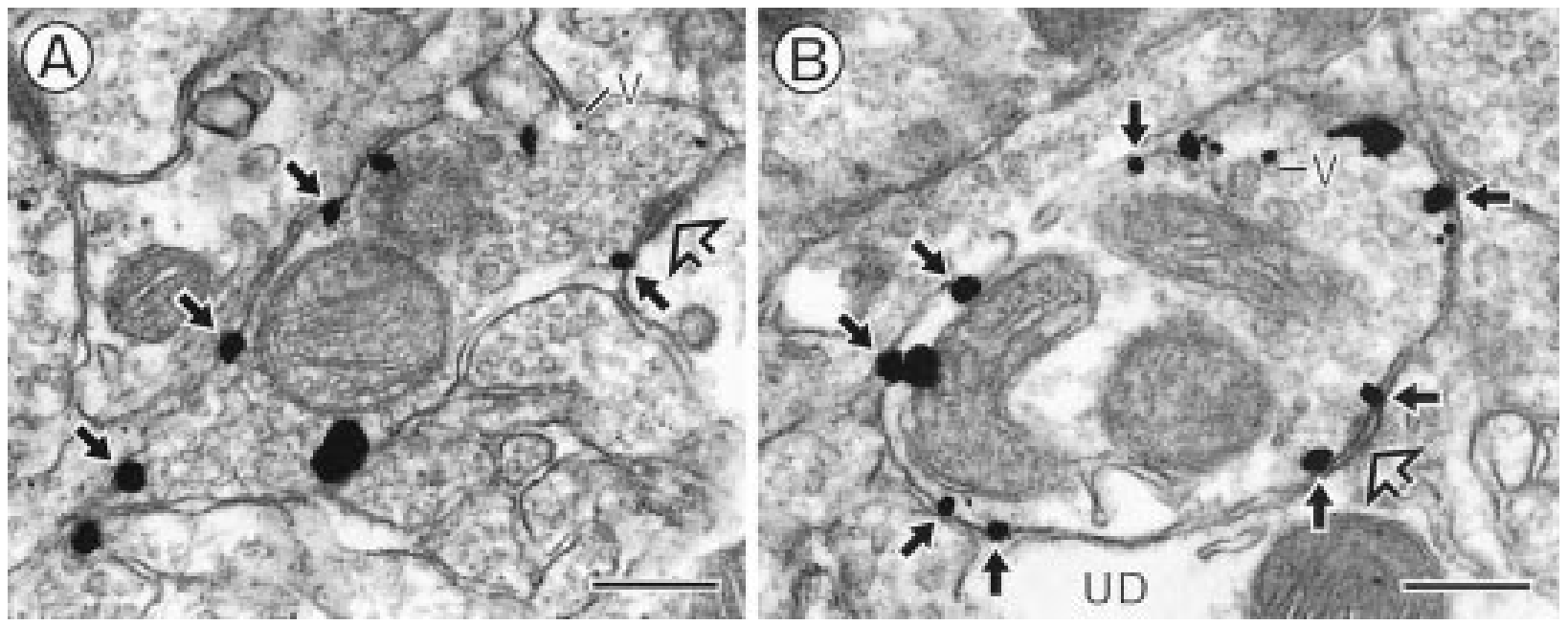

Figure 5. DAT labeling on extrasynaptic plasma membranes of axon terminals. Electron micrographs show tissue that has been singly labeled with immunogold for DAT, derived from the NAc core $(A)$ and shell $(B)$. In $A$, immunogold labeling for DAT (closed arrows) is located on extrasynaptic portions of the plasma membrane of an axon terminal in the NAc core. The labeled terminal forms a symmetric synapse (open arrow) onto an unlabeled dendrite. In $B$, the primary DAT antiserum has been used at twice the concentration as in $A$. Immunogold labeling for DAT (closed arrows) is located on extrasynaptic portions of the plasma membrane of an axon terminal in the NAc shell. The labeled terminal forms a symmetric synapse (open arrow) onto the spine of an unlabeled dendrite (UD). In $A$ and $B$, several plasmalemmal DAT gold particles are seen just lateral to the synaptic junctions, whereas others contact electron-lucent intracellular vesicles $(V)$. Scale bars, $0.25 \mu \mathrm{m}$.

and included structures that resembled SSVs (Fig. 5B), as well as larger ( $>70 \mathrm{~nm}$ in maximal cross-sectional diameter) tubulovesicular organelles (results not shown). DCVs were infrequently detected within the DAT-immunoreactive axons and never contained detectable DAT immunoreactivity.

\section{Appositions with other catecholaminergic axons}

In both the core (Fig. $6 A$ ) and shell (Fig. $6 B$ ), some of the axons that were dually labeled for DAT and TH were apposed to other dually labeled axons. In addition, in the shell (Fig. 7), but only rarely in the core, dually labeled (DAT/TH) axons were often apposed to axons that were singly labeled with peroxidase for $\mathrm{TH}$. When the appositions between DAT/TH- and either DAT/THor TH-labeled axons occurred, the plasmalemmal immunogold labeling for DAT was observed at the sites of apposition (Figs. 6, 7 ), as well as distant from these contacts (Figs. 6A, 7B).

\section{Quantitative comparison of the core and shell}

DAT-immunoreactive axons in the NAc shell contained a significantly lower mean density of total DAT gold particles per unit area $\left(15.2 \pm 0.7 / \mu \mathrm{m}^{2}\right)$ than those in the core $\left(22.0 \pm 0.7 / \mu \mathrm{m}^{2} ; p<\right.$ 0.001 ) (Fig. 8A). The plasma membranes of the DATimmunoreactive axons in the shell also contained a lower density of DAT gold particles per unit perimeter $(12.4 \pm 0.5 / \mu \mathrm{m})$ than those in the core $(17.3 \pm 0.6 / \mu \mathrm{m} ; p<0.001)$ (Fig. $8 B)$. In contrast, the proportion of DAT gold particles that were located on plasma membranes in the shell and core did not differ significantly (75 \pm $2 \%$ and $78 \pm 1 \%$, respectively; $p>0.1$ ).

\section{DISCUSSION}

Our results provide the first ultrastructural evidence that DAT is present along extrasynaptic plasma membranes of $\mathrm{TH}-$ immunoreactive axons in the limbic shell and motor-associated core of the NAc. They also identify cell-specific differences in the density of plasmalemmal and cytoplasmic DAT within individual axons in these regions. The presence of lower densities of DAT within dopaminergic axons in the NAc shell is likely to play a

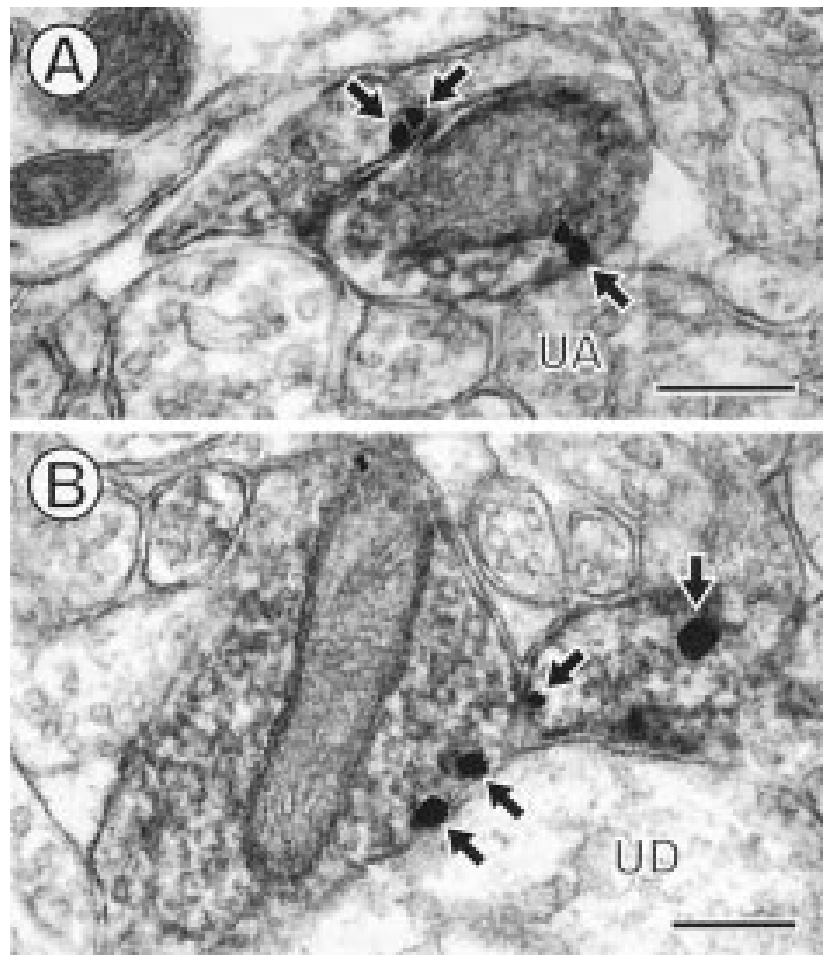

Figure 6. Appositions between axons labeled for both DAT and TH. Electron micrographs show immunogold labeling for DAT (arrows) and immunoperoxidase labeling for TH within two apposed axons in the NAc core $(A)$ and shell $(B)$. Some of the DAT gold particles in $A$ and $B$ are seen at the appositions between labeled axons, whereas others are distant from these contacts. In $B$, the dually labeled terminals also contact a common unlabeled dendrite $(U D)$. $U A$, Unlabeled axon. Scale bars, $0.25 \mu \mathrm{m}$.

significant role in determining regional differences in extracellular dopamine diffusion, sensitivity to psychostimulants, and susceptibility to neurotoxins. 


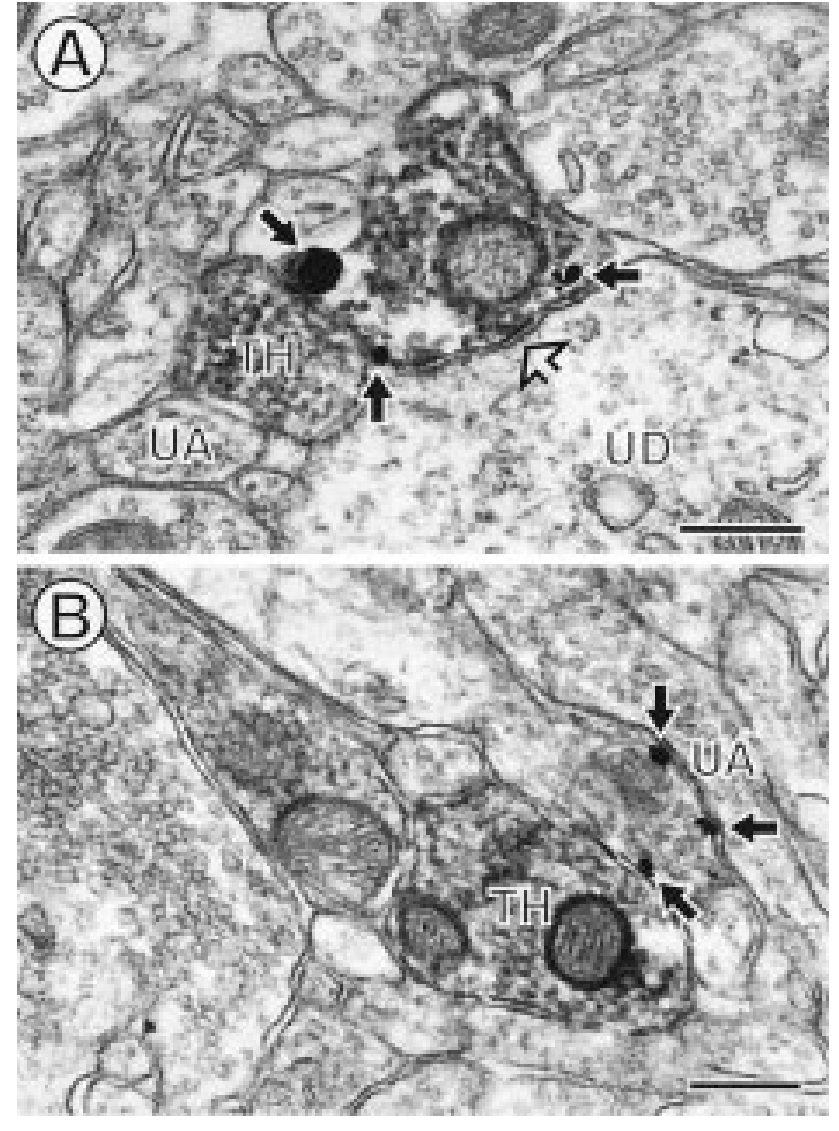

Figure 7. Appositions between TH-immunoreactive axons, only one of which contains DAT labeling. Electron micrographs show immunogold labeling for DAT (closed arrows) and immunoperoxidase labeling for TH in axons in the NAc shell. Each of the dually labeled axons is apposed to another axon that is singly labeled with peroxidase reaction product for $\mathrm{TH}(T H)$. Some of the plasmalemmal DAT gold particles are seen near the points of apposition, whereas others are distant from these contacts. In $A$, the dually labeled axon forms a symmetric synapse (open arrow) onto an unlabeled dendrite $(U D)$. This unlabeled dendrite is also apposed to the TH-labeled axon (TH). $U A$, Unlabeled axon. Scale bars, $0.25 \mu \mathrm{m}$.

\section{Regional heterogeneity of DAT}

We have shown that there is a lower density of DAT gold particles per unit perimeter on plasma membranes of dopaminergic axons in the NAc shell than in the core. This is the first direct evidence that there are intrinsic differences in the expression of this protein within individual dopaminergic axons in limbic and motorassociated NAc compartments. Dopaminergic axons in the shell also contained lower total levels of DAT immunoreactivity per unit area, suggesting that these cell-specific differences are attributable to the presence of lower steady-state levels of total DAT protein within axons in the NAc shell than in the core. This interpretation is supported by previous observations that DAT mRNA is less abundant in cells of origin in the VTA than in those in the SN (Shimada et al., 1992; Cerruti et al., 1993; Blanchard et al., 1994; Uhl et al., 1994; Haber et al., 1995). In contrast, although recent in vitro studies suggest that the sorting of DAT to plasma membranes may display some cell-type specificity ( $\mathrm{Gu}$ et al., 1996), we found no detectable differences in the proportion of DAT immunoreactivity that was localized to plasma membranes of dopaminergic axons in the two regions. Together, these findings suggest that the reduced expression of functional dopamine
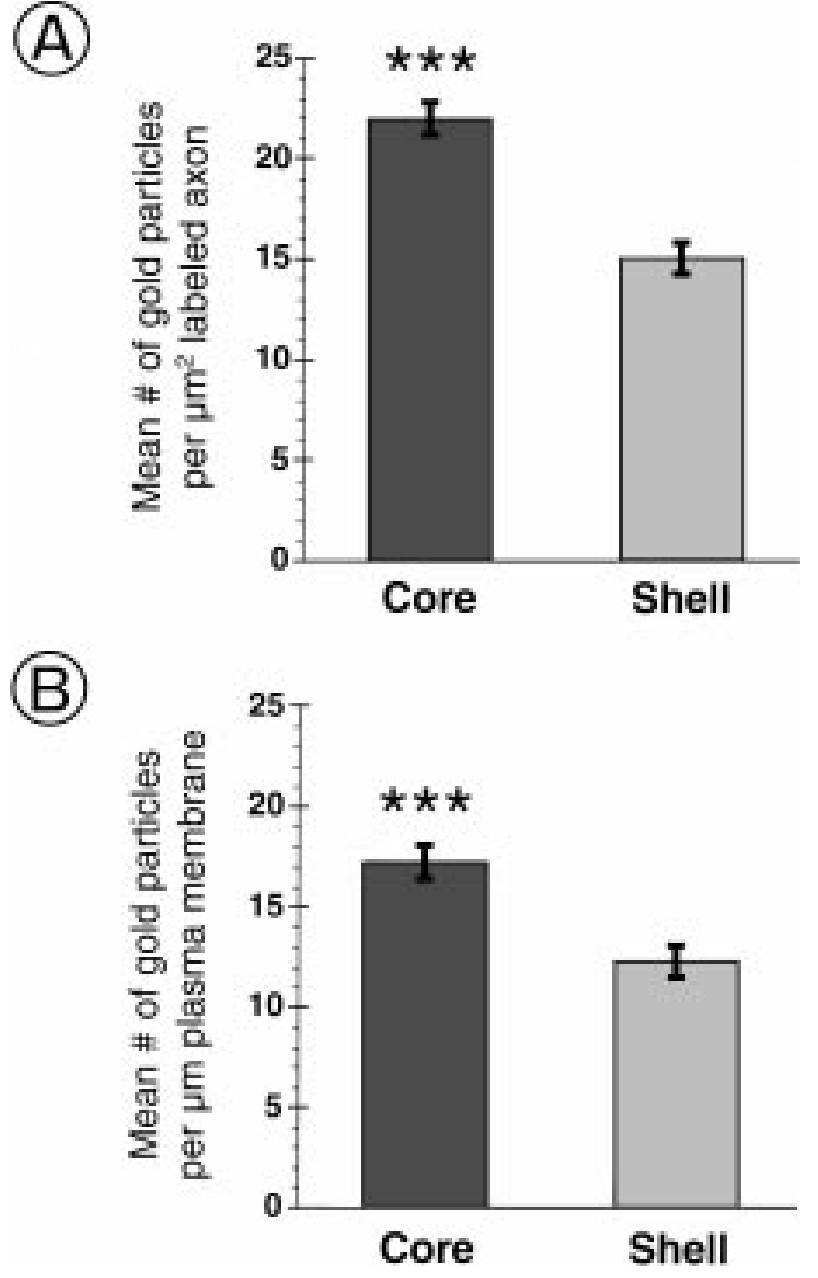

Figure 8. DAT-immunoreactive axons in the NAc shell contain lower densities of DAT than those in the core. $A$, Bar graph showing a higher mean number of total DAT gold particles per unit area within labeled axons in the NAc core $\left(22.0 \pm 0.7 / \mu \mathrm{m}^{2}\right)$ than in the shell $\left(15.2 \pm 0.7 / \mu \mathrm{m}^{2}\right.$; $p<0.001)$. $B$, Bar graph showing a higher mean number of plasmalemmal DAT gold particles per unit perimeter of plasma membrane within labeled axons in the NAc core $(17.3 \pm 0.6 / \mu \mathrm{m})$ than in the shell $(12.4 \pm$ $0.5 / \mu \mathrm{m} ; p<0.001)$. Asterisks in $A$ and $B$ indicate statistically significant differences.

uptake sites in the NAc shell results from the presence of a lower mean density of DAT within individual dopaminergic axons in this region.

\section{Extrasynaptic dopaminergic transmission}

DAT immunoreactivity was detected mainly on extrasynaptic plasma membranes of dopaminergic axons, and less frequently on intracellular membranes, in both the core and shell of the NAc. Although we cannot rule out the possibility that DAT may be present at synaptic densities but undetectable by pre-embedding immunocytochemical techniques (Nusser et al., 1995), previous studies with antisera directed against the N-terminal domain (Nirenberg et al., 1996a) and the second extracellular loop of DAT (Hersch et al., 1995) have shown that DAT labeling is present in a comparable distribution on extrasynaptic plasma membranes of axons in the dorsal striatum. These findings suggest that the absence of labeling at the synapse is not attributable to selective loss or masking of the N-terminal domain. In addition, they demonstrate that the subcellular localization of DAT is qualitatively similar in the dorsal and ventral striatum. 
The observed extrasynaptic localization of DAT provides direct anatomical confirmation that dopamine uptake sites in the NAc are located extensively, and perhaps exclusively, outside the synapse (for review, see Pickel et al., 1996). Previous studies have demonstrated that there are physiologically relevant concentrations of dopamine present in the neuropil in the NAc, suggesting that dopamine can diff use out of the synaptic cleft (Parsons and Justice, 1992). Moreover, the efflux of dopamine from synapses in this region can be detected after a single electrical stimulus (Garris et al., 1994). Because uptake is the most important mechanism for the clearance of dopamine from the extracellular space, extrasynaptic dopamine uptake sites are likely to regulate the diff usion of dopamine into the neuropil, as well as the amount of this transmitter that can reach dopamine receptors located distant from synaptic specializations (Levey et al., 1993; Sesack et al., 1994; Yung et al., 1995). Accordingly, the presence of lower densities of DAT within dopaminergic axons in the NAc shell, suggested by the presence of less DAT labeling on these axons, is likely to contribute to the reduced efficiency of dopamine uptake observed in this region (Jones et al., 1996). These differences may also account for the increased diff usion radius of dopamine in the NAc shell (Garris et al., 1994). Thus, the prevalence of extrasynaptic DAT immunolabeling indicates sites whereby DAT has the potential to differentially regulate volume transmission in the NAc shell and core (Schmitt, 1984; Herkenham, 1987; for review, see Pickel et al., 1996).

\section{Reciprocal relationships between catecholaminergic axons}

Appositions between DAT-immunoreactive axons were frequently observed in both the shell and the core of the NAc. The presence of DAT immunogold particles at points of contact between apposed DAT-immunoreactive axons suggests the possibility that dopamine synthesized in one axon and released into the extracellular space could be taken up in an adjacent dopaminergic axon. This may be a general characteristic of mesolimbic dopaminergic neurons, because in previous studies we have shown that similar appositions also frequently occur between DAT-immunoreactive dendrites in the VTA (Nirenberg et al., 1997).

In the NAc shell, many of the DAT/TH-labeled axons were apposed to axons that were singly labeled for TH. These THimmunoreactive axons presumably include dopaminergic axons that lack DAT labeling in the observed plane of section, because our results suggest that there may be differential subcellular distributions of these proteins within individual axons. In addition, some of the TH-immunoreactive processes without DAT labeling may represent noradrenergic axons, which are known to innervate the NAc shell (Kelley et al., 1996; Saleem et al., 1996) and to modulate extracellular dopamine levels in other limbic and forebrain regions (Gresch et al., 1995). Thus, these appositions may represent sites of interaction between dopaminergic and noradrenergic neurons in this region.

\section{Implications for sensitivity to psychostimulants}

The sensitivity of dopaminergic neurons to psychostimulants is believed to be a function of the number of plasmalemmal uptake sites available for these drugs to inhibit (Cass et al., 1993; Mash and Staley, 1997). Regional differences in the sensitivity to psychostimulants have been demonstrated; however, there are conflicting reports as to whether the shell (Pontieri et al., 1995) or the core (Jones et al., 1996) is more sensitive. Our findings indicate that these regional differences might potentially result from the presence of fewer total transporters in the shell (Jones et al., 1996) or from greater "transporter saturation" in the shell resulting from a higher ratio of dopamine release to reuptake within dopaminergic axons in this region (Pontieri et al., 1995).

We have also revealed more subtle features of the NAc shell and core that may contribute to the differential sensitivity to psychostimulants in these regions. In particular, we have identified potential sites for functional interactions between dopaminergic and noradrenergic axons in the NAc shell but not the core. These unique cellular relationships might potentially result in differences in the indirect effects of cocaine on dopaminergic transmission in these regions (Li et al., 1996). We have also shown that the plasma membranes of individual dopaminergic axons in the NAc shell contain lower densities of DAT than those in the core. These differences are likely to affect both the baseline membrane properties of the dopaminergic neurons in the two regions and the capacity for these properties to be altered by psychostimulants that block DAT-associated currents (Povlock and Amara, 1997). Together, these regional and cell-specific differences in expression of DAT are likely to play critical roles in determining the differential sensitivity of the NAc core and shell to cocaine and other psychostimulants.

\section{Implications for neurotoxicity}

Dopaminergic neurons also show regional heterogeneity with respect to their sensitivity both to parkinsonism-inducing neurotoxins and to idiopathic Parkinson's disease (for review, see Roth and Elsworth, 1995). Given the established role of the dopamine transporter in the uptake of toxins such as 1-methyl-4phenylpyridinium and 6-OHDA (Javitch et al., 1985; Sundstrom et al., 1986; Kitayama et al., 1992, 1993; Pifl et al., 1993), it has been suggested that the relative resistance of mesolimbic dopaminergic neurons to these toxins might result from the presence of fewer dopamine uptake sites in the NAc shell compared with the core and caudate-putamen nucleus (for review, see Edwards, 1993; Uhl et al., 1994). For the presence of fewer dopamine uptake sites in the NAc shell to confer relative resistance to these toxins, however, there would have to be lower densities of DAT within individual axons in this region.

In the present study, we provide direct evidence that individual dopaminergic axons in the NAc shell contain both lower total densities of DAT and lower densities of DAT on the plasma membrane. These cell-specific differences in DAT expression may underlie the relative resistance of individual dopaminergic axons in the NAc shell to neurotoxic insult. Interestingly, in our previous ultrastructural studies of the vesicular monoamine transporter-2, a transporter that has been implicated in neuroprotection through sequestration of toxins, we showed that there are higher levels of this transporter in the dendrites of mesolimbic compared with nigrostriatal dopaminergic neurons (Nirenberg et al., 1996b). Together, these findings show that differential expression of both vesicular and plasmalemmal dopamine transporters may contribute to the relative resistance of mesolimbic dopaminergic neurons to neurotoxic insult.

\section{REFERENCES}

Bannon MJ, Granneman JG, Kapatos G (1995) The dopamine transporter: potential involvement in neuropsychiatric disorders. In: Psychopharmacology: the fourth generation of progress (Bloom FE, Kupfer DJ, eds), pp 179-188. New York: Raven.

Blanchard V, Raisman-Vozari R, Vyas S, Michel PP, Javoy-Agid F, Uhl G, Agid Y (1994) Differential expression of tyrosine hydroxylase and membrane dopamine transporter genes in subpopulations of dopaminergic neurons of the rat mesencephalon. Mol Brain Res 22:29-38. 
Cass WA, Zahniser NR, Flach KA, Gerhardt GA (1993) Clearance of exogenous dopamine in rat dorsal striatum and nucleus accumbens: role of metabolism and effects of locally applied uptake inhibitors. J Neurochem 61:2269-2278.

Cerruti C, Walther DM, Kuhar MJ, Uhl GR (1993) Dopamine transporter mRNA expression is intense in rat midbrain neurons and modest outside midbrain. Mol Brain Res 18:181-186.

Chan J, Aoki C, Pickel VM (1990) Optimization of differential immunogold-silver and peroxidase labeling with maintenance of ultrastructure in brain sections before plastic embedding. J Neurosci Methods 33:113-127.

Deutch AY, Cameron DS (1992) Pharmacological characterization of dopamine systems in the nucleus accumbens core and shell. Neuroscience 46:49-56.

Edwards RH (1993) Neuronal degeneration and the transport of neurotransmitters. Ann Neurol 34:638-645.

Fibiger HC, Phillips AG, Brown EE (1992) The neurobiology of cocaine-induced reinforcement. Ciba Found Symp 166:96-111.

Freed C, Revay R, Vaughan RA, Kriek E, Grant S, Uhl GR, Kuhar MJ (1995) Dopamine transporter immunoreactivity in rat brain. J Comp Neurol 359:340-349.

Garris PA, Ciolkowski EL, Pastore P, Wightman RM (1994) Efflux of dopamine from the synaptic cleft in the nucleus accumbens of the rat brain. J Neurosci 14:6084-6093.

Giros B, El Mestikawy S, Bertrand L, Caron G (1991) Cloning and functional characterization of a cocaine-sensitive dopamine transporter. FEBS Lett 295:149-154.

Giros B, Jaber M, Jones SR, Wightman RM, Caron MG (1996) Hyperlocomotion and indifference to cocaine and amphetamine in mice lacking the dopamine transporter. Nature 379:606-612.

Gresch PJ, Sved AF, Zigmond MJ, Finlay JM (1995) Local influence of endogenous norepinephrine on extracellular dopamine in medial prefrontal cortex. J Neurochem 65:111-116.

Gu HH, Ahn J, Caplan MJ, Blakely RD, Levey AI, Rudnick G (1996) Cell-specific sorting of biogenic amine transporters expressed in epithelial cells. J Biol Chem 271:18100-18106.

Haber SN, Ryoo H, Cox C, Lu W (1995) Subsets of midbrain dopaminergic neurons in monkeys are distinguished by different levels of mRNA for the dopamine transporter-comparison with the mRNA for the D-2 receptor, tyrosine hydroxylase and calbindin immunoreactivity. J Comp Neurol 362:400-410.

Heimer L, Zahm DS, Churchill L, Kalivas PW, Wohltmann C (1991) Specificity of the projection patterns of accumbal core and shell in the rat. Neuroscience 41:89-125.

Herkenham M (1987) Mismatches between neurotransmitter and receptor localizations in brain: observations and implications. Neuroscience 23:1-38.

Hersch SM, Yi H, Ciliax BJ, Levey AI (1995) Electron microscopic localization of the dopamine transporter in the striatum and substantia nigra. Soc Neurosci Abstr 21:781.

Horn AS (1990) Dopamine uptake: a review of progress in the last decade. Prog Neurobiol 34:387-400.

Hsu SM, Raine L, Fanger H (1981) The use of avidin-biotin-peroxidase complex $(\mathrm{ABC})$ in immunoperoxidase technique: a comparison between $\mathrm{ABC}$ and unlabeled antibody (peroxidase) procedures. J Histochem Cytochem 29:577-599.

Javitch JA, D'Amato RJ, Strittmatter SM, Snyder SH (1985) Parkinsonism-inducing neurotoxin, $N$-methyl-4-phenyl-1,2,3,6-tetrahydropyridine: uptake of the metabolite $N$-methyl-4-phenylpyridine by dopamine neurons explains selective toxicity. Proc Natl Acad Sci USA 82:2173-2177.

Jones SR, O'Dell SJ, Marshall JF, Wightman RM (1996) Functional and anatomical evidence for different dopamine dynamics in the core and shell of the nucleus accumbens in slices of rat brain. Synapse 23:224-231.

Jongen-Relo AL, Voorn P, Groenewegen HJ (1994) Immunohistochemical characterization of the shell and core territories of the nucleus accumbens in the rat. Eur J Neurosci 6:1255-1264.

Kelley AE, Stratford TR, Foote SL, Berridge CW (1996) Distribution of dopamine-beta-hydroxylase-like immunoreactive fibers within the nucleus accumbens shell. Soc Neurosci Abstr 21:602.

Kilty JE, Lorang D, Amara SG (1991) Cloning and expression of a cocaine-sensitive rat dopamine transporter. Science 254:578-579.

Kitayama S, Shimada S, Uhl GR (1992) Parkinsonism-inducing neuro- toxin $\mathrm{MPP}^{+}$: uptake and toxicity in nonneuronal COS cells expressing dopamine transporter cDNA. Ann Neurol 32:109-111.

Kitayama S, Wang JB, Uhl GR (1993) Dopamine transporter mutants selectively enhance $\mathrm{MPP}^{+}$transport. Synapse 15:58-62.

Koob GF, Bloom FE (1988) Cellular and molecular mechanisms of drug dependence. Science 242:715-723.

Kuhar MJ, Ritz MC, Boja JW (1991) The dopamine hypothesis of the reinforcing properties of cocaine. Trends Neurosci 14:299-302.

Le Moal M (1995) Mesocorticolimbic dopaminergic neurons: functional and regulatory roles. In: Psychopharmacology: the fourth generation of progress (Bloom FE, Kupfer DJ, eds), pp 283-294. New York: Raven.

Leranth C, Pickel VM (1989) Electron microscopic pre-embedding double immunostaining methods. In: Neuroanatomical tract-tracing methods. II. Recent progress (Heimer L, Zaborsky L, eds), pp 129-172. New York: Plenum.

Levey AI, Hersch SM, Rye DB, Sunahara RK, Niznik HB, Kitt CA, Price DL, Maggio R, Brann MR, Ciliax BJ (1993) Localization of D1 and D2 dopamine receptors in brain with subtype-specific antibodies. Proc Natl Acad Sci USA 90:8861-8865.

Li MY, Yan QS, Coffey LL, Reith ME (1996) Extracellular dopamine, norepinephrine, and serotonin in the nucleus accumbens of freely moving rats during intracerebral dialysis with cocaine and other monoamine uptake blockers. J Neurochem 66:559-568.

Mash DC, Staley JK (1997) The dopamine transporter in human brain. In: Neurotransmitter transporters: structure, function, and regulation (Reith MEA, ed), pp 315-343. Totowa, NJ: Humana.

Nirenberg MJ, Pickel VM (1997) Vesicular and plasmalemmal dopamine transporters: ultrastructural localization in nigrostriatal dopaminergic neurons. In: Proceedings of the NATO Advanced Research Workshop on Neurotransmitter Release and Uptake (Pögün S, ed), pp 193-208. Heidelberg: Springer.

Nirenberg MJ, Vaughan RA, Uhl GR, Kuhar MJ, Pickel VM (1996a) The dopamine transporter is localized to dendritic and axonal plasma membranes of nigrostriatal dopaminergic neurons. J Neurosci $16: 436-447$.

Nirenberg MJ, Chan J, Liu Y, Edwards RH, Pickel VM (1996b) Ultrastructural localization of the vesicular monoamine transporter-2 in midbrain dopaminergic neurons: potential sites for somatodendritic storage and release of dopamine. J Neurosci 16:4135-4145.

Nirenberg MJ, Chan J, Vaughan RA, Uhl GR, Kuhar MJ, Pickel VM (1997) Immunogold localization of the dopamine transporter: an ultrastructural study of the rat ventral tegmental area. J Neurosci 17:5255-5262.

Nusser Z, Roberts JDB, Baude A, Richards JG, Somogyi P (1995) Relative densities of synaptic and extrasynaptic $\mathrm{GABA}_{\mathrm{A}}$ receptors on cerebellar granule cells as determined by a quantitative immunogold method. J Neurosci 15:2948-2960.

O'Donnell P, Grace AA (1993) Physiological and morphological properties of accumbens core and shell neurons recorded in vitro. Synapse 13:135-160.

Parsons LH, Justice Jr JB (1992) Extracellular concentration and in vivo recovery of dopamine in the nucleus accumbens using microdialysis. J Neurochem 58:212-218.

Paxinos G, Watson C (1986) The rat brain in stereotaxic coordinates. Orlando, FL: Academic.

Peters A, Palay SL, Webster HD (1991) The fine structure of the nervous system. New York: Oxford UP.

Pickel VM, Sesack SR (1995) Electron microscopy of central dopamine systems. In: Psychopharmacology: the fourth generation of progress (Bloom FE, Kupfer DJ, eds), pp 257-268. New York: Raven.

Pickel VM, Nirenberg MJ, Milner TA (1996) Ultrastructural view of central catecholaminergic transmission: immunocytochemical localization of synthesizing enzymes, transporters, and receptors. J Neurocytol 25:843-856.

Pierce RC, Kalivas PW (1995) Amphetamine produces sensitized increases in locomotion and extracellular dopamine preferentially in the nucleus accumbens shell of rats administered repeated cocaine. J Pharmacol Exp Ther 275:1019-1029.

Pifl C, Giros B, Caron MG (1993) Dopamine transporter expression confers cytotoxicity to low doses of the parkinsonism-inducing neurotoxin 1-methyl-4-phenylpyridinium. J Neurosci 13:4246-4253.

Pilotte NS, Sharpe LG, Rountree SD, Kuhar MJ (1996) Cocaine withdrawal reduces dopamine transporter binding in the shell of the nucleus accumbens. Synapse 22:87-92.

Pontieri FE, Colangelo V, La Riccia M, Pozzilli C, Passarelli F, Orzi F 
(1994) Psychostimulant drugs increase glucose utilization in the shell of the rat nucleus accumbens. NeuroReport 5:2561-2564.

Pontieri FE, Tanda G, Di CG (1995) Intravenous cocaine, morphine, and amphetamine preferentially increase extracellular dopamine in the "shell" as compared with the "core" of the rat nucleus accumbens. Proc Natl Acad Sci USA 92:12304-12308.

Povlock SL, Amara SG (1997) The structure and function of norepinephrine, dopamine, and serotonin transporters. In: Neurotransmitter transporters: structure, function, and regulation (Reith MEA, ed), pp 1-28. Totowa, NJ: Humana.

Revay R, Vaughan R, Grant S, Kuhar MJ (1996) Dopamine transporter immunohistochemistry in median eminence, amygdala, and other areas. Synapse 22:93-99.

Ritz MC, Lamb RJ, Goldberg SR, Kuhar MJ (1987) Cocaine receptors on dopamine transporters are related to self-administration of cocaine. Science 237:1219-1223.

Roth RH, Elsworth JD (1995) Biochemical pharmacology of midbrain dopamine neurons. In: Psychopharmacology: the fourth generation of progress (Bloom FE, Kupfer DJ, eds), pp 227-243. New York: Raven.

Saleem A, Zhu Y, Druhan J, Aston-Jones G (1996) Innervation of the nucleus accumbens shell and ventral tegmental area by dopamine beta-hydroxylase-positive fibers: possible sites for norepinephrinedopamine interactions. Soc Neurosci Abstr 21:602.

Schmitt FO (1984) Molecular regulators of brain function: a new view. Neuroscience 13:991-1001.

Sesack SR, Aoki C, Pickel VM (1994) Ultrastructural localization of D2 receptor-like immunoreactivity in midbrain dopamine neurons and their striatal targets. J Neurosci 14:88-106.

Sharpe LG, Pilotte NS, Mitchell WM, De SE (1991) Withdrawal of repeated cocaine decreases autoradiographic $\left[{ }^{3} \mathrm{H}\right]$ mazindol-labelling of dopamine transporter in rat nucleus accumbens. Eur J Pharmacol 203:141-144.
Shimada S, Kitayama S, Lin CL, Patel A, Nanthakumar E, Gregor P, Kuhar M, Uhl G (1991) Cloning and expression of a cocaine-sensitive dopamine transporter complementary DNA. Science [Erratum (1992) 255:1195] 254:576-578.

Shimada S, Kitayama S, Walther D, Uhl G (1992) Dopamine transporter mRNA: dense expression in ventral midbrain neurons. Mol Brain Res 13:359-362.

Sundstrom E, Goldstein M, Jonsson G (1986) Uptake inhibition protects nigro-striatal dopamine neurons from the neurotoxicity of 1-methyl-4phenylpyridine $\left(\mathrm{MPP}^{+}\right)$in mice. Eur J Pharmacol 131:289-292.

Swanson, LW (1992) Brain maps: structure of the rat brain. Amsterdam: Elsevier.

Uhl GR, Walther D, Mash D, Faucheux B, Javoy-Agid F (1994) Dopamine transporter messenger RNA in Parkinson's disease and control substantia nigra neurons. Ann Neurol 35:494-498.

Voorn P, Gerfen CR, Groenewegen HJ (1989) Compartmental organization of the ventral striatum of the rat: immunohistochemical distribution of enkephalin, substance $\mathrm{P}$, dopamine, and calcium-binding protein. J Comp Neurol 289:189-201.

Yung KK, Bolam JP, Smith AD, Hersch SM, Ciliax BJ, Levey AI (1995) Immunocytochemical localization of D1 and D2 dopamine receptors in the basal ganglia of the rat: light and electron microscopy. Neuroscience 65:709-30.

Zahm DS (1991) Compartments in rat dorsal and ventral striatum revealed following injection of 6-hydroxydopamine into the ventral striatum. Brain Res 552:164-169.

Zahm DS, Brog JS (1992) On the significance of subterritories in the "accumbens" part of the rat ventral striatum. Neuroscience 50:751-767.

Zahm DS, Heimer L (1993) Specificity in the efferent projections of the nucleus accumbens in the rat: comparison of the rostral pole projection patterns with those of the core and shell. J Comp Neurol 327:220-232. 